\title{
Validation study for the hypothesis of internal mammary sentinel lymph node lymphatic drainage in breast cancer
}

\author{
Bin-Bin Cong1,2, Peng-Fei Qiư2, Yan-Bing Liư ${ }^{2}$, Tong Zhao², Peng Chen², Xiao- \\ Shan $\mathrm{Cao}^{1,2}$, Chun-Jian Wang ${ }^{2}$, Zhao-Peng Zhang', Xiao Sun ${ }^{2}$, Jin-Ming $\mathbf{Y u}^{3,}{ }^{3}$, \\ Yong-Sheng Wang ${ }^{2, *}$ \\ ${ }^{1}$ School of Medicine and Life Sciences, University of Jinan and Shandong Academy of Medical Sciences, Jinan, Shandong, China \\ ${ }^{2}$ Breast Cancer Center, Shandong Cancer Hospital Affiliated to Shandong University, Jinan, Shandong, China \\ ${ }^{3}$ Department of Radiotherapy, Shandong Cancer Hospital Affiliated to Shandong University, Jinan, Shandong, China \\ *These authors have contributed equally to this work \\ Correspondence to: Yong-Sheng Wang, email: wangysh2008@aliyun.com \\ Jin-Ming Yu, email: sdyujinming@126.com \\ Keywords: breast cancer, internal mammary, sentinel lymph node biopsy, visualization rate, indocyanine green \\ Received: January 13, $2016 \quad$ Accepted: May 09, $2016 \quad$ Published: May 26, 2016
}

\section{ABSTRACT}

According to axilla sentinel lymph node lymphatic drainage pattern, we hypothesized that internal mammary sentinel lymph node (IM-SLN) receives lymphatic drainage from not only the primary tumor area, but also the entire breast parenchyma. Based on the hypothesis a modified radiotracer injection technique was established and could increase the visualization rate of the IM-SLN significantly. To verify the hypothesis, two kinds of tracers were injected at different sites of breast. The radiotracer was injected with the modified technique, and the fluorescence tracer was injected in the peritumoral intra-parenchyma. The location of IM-SLN was identified by preoperative lymphoscintigraphy and intraoperative gamma probe. Then, internal mammary sentinel lymph node biopsy (IM-SLNB) was performed. The fluorescence status of IM-SLN was identified by the fluorescence imaging system. A total of 216 patients were enrolled from September 2013 to July 2015. The overall visualization rate of IM-SLN was $71.8 \%$ $(155 / 216)$. The success rate of IM-SLNB was $97.3 \%(145 / 149)$. The radiotracer and the fluorescence tracer were identified in the same IM-SLN in 127 cases, the correlation and the agreement is significant (Case-base, $r_{s}=0.836, P<0.001 ; K a p p a=0.823, P<0.001$ ). Different tracers injected into the different sites of the intra-parenchyma reached the same IM-SLN, which demonstrates the hypothesis that IM-SLN receives the lymphatic drainage from not only the primary tumor area but also the entire breast parenchyma.

\section{INTRODUCTION}

Internal mammary lymph node (IMLN) metastasis has a similar prognostic importance as axillary lymph node (ALN) involvement in breast cancer patients [1-3]. Internal mammary sentinel lymph node biopsy (IM-SLNB) was a minimally invasive technique for the efficient evaluation of the status of internal mammary sentinel lymph nodes (IM-SLN) with high safety and feasibility $[4,5]$. The success rate of IM-SLNB has reached $60-100 \%$ with minimal or no changes in operative time [4-7], but the visualization rate of IM-SLN was low (average 13\%, range $0-37 \%$ ) by the traditional injection technique [6-8].
According to the axilla sentinel lymph node (ASLN) lymphatic drainage pattern (i.e., ASLN receives lymphatic drainage from not only the primary tumor area, but also the entire breast) $[9,10]$, we hypothesized that IM-SLN receives lymphatic drainage from not only the primary tumor area, but also the entire breast parenchyma [8]. Based on the hypothesis, a modified radiotracer injection technique has been established which increased the visualization rate of the IM-SLN significantly [8]. The hypothesis needs to be demonstrated. To avoid more injury by complete IMLN dissection following IM-SLNB, an alternative validation study for the hypothesis was performed: two different tracers were injected in different sites of the intra-parenchyma to observe whether they could reach to the same IM-SLN. 


\section{RESULTS}

\section{Characteristics of IM-SLNB}

The clinically pathological characteristics of the 216 enrolled patients are presented in Table 1 . The detection rate of ASLN was 98.6\% (213/216). The overall visualization rate of IM-SLN detected by preoperative lymphoscintigraphy and gamma probe was $71.8 \%(155 / 216) .96 .1 \%(149 / 155)$ of them received IM-SLNB. The success rate of IM-SLNB was $97.3 \%$ $(145 / 149)$. The data on clinical outcome of the patients underwent IM-SLNB show in Table 2. In 12 patients underwent breast conserving surgery, 5 cases who were identified the location of primary tumor could not reach IM-SLNB had to be made an extra incision in the skin to reach IM-SLNB.

In patients who performed IM-SLNB successfully, a total of 279 lymph nodes were removed, the median number of IM-SLNs was 2 (range 1-4 nodes). The IMSLNs were located in the first $(5.4 \%, 15 / 279)$, second $(46.2 \%, 129 / 279)$, third $(40.5 \%, 113 / 279)$ and forth $(7.9 \%, 22 / 279)$ intercostal space. All positive IM-SLNs were in the second $(61.1 \%, 11 / 18)$ and the third $(38.9 \%$, $7 / 18)$ intercostal space. $54.1 \%(151 / 279)$ of IM-SLN was found in the outside of the internal mammary vessels and $45.9 \%$ (128/279) was in the inside. Details of IM-SLN mapping and biopsy are shown in Table 3. The IM-SLN involvement rate was $8.1 \%(7 / 86)$ in patient with clinically axillary node negative patients and $18.6 \%(11 / 59)$ in positive patients respectively. All patients with positive IM-SLN received regional nodal irradiation to IMLNs. The clinical, pathological and treatment details of these patients were shown in Table 4 . In patients with $\geq 4$ positive axillary lymph nodes, regional nodal irradiation to IMLNs had been avoided in $50.0 \%$ cases $(9 / 18)$ with negative IM-SLN. In patients with 1-3 positive axillary lymph nodes, regional nodal irradiation to IMLNs might be avoided in $91.2 \%$ cases $(52 / 57)$ with negative IM-SLN.

\section{Correlation and agreement between the radiotracer and the fluorescence tracer}

In the validation study, 145 patients underwent IMSLNB successfully, of which 127 patients identified the radiotracer and the fluorescence tracer reached to the same IM-SLN, 18 patients were detected only the radiotracer positive IM-SLN (Table 5). Accordingly, the radiotracer and the fluorescence tracer in the same IM-SLN showed a strong correlation coefficient at 0.836 (Case-base, $\mathrm{r}_{\mathrm{s}} \geq 0.5$, $P<0.05)$. The degree of agreement between the radiotracer and the fluorescence tracer was Kappa $=0.823$ (very good), showing high degree of agreement between the two tracers (Kappa $>0.8, P<0.05$ ).

\section{Complications}

No serious bleeding and pain was found after using the modified radiotracer injection technique in all patients. A total of 2 patients were found with minor generalized skin reactions which occurred after injection of indocyanine green (ICG) during the surgery. A small pleural lesion $(\leq 2 \mathrm{~mm})$ was noted intraoperatively in $1.4 \%$ cases $(2 / 145)$ and no pneumothorax was seen postoperatively on chest $\mathrm{X}$-rays. Intraoperative bleeding from the internal mammary artery occurred in $3.4 \%$ cases (5/145), and was successfully resolved. There were no postoperative complications and reactions after the two-week following up, and no increase of days in hospital stay from this procedure.

\section{DISCUSSION}

IMLN metastases have been demonstrated to occur in $28-52 \%$ of ALN positive patients and $5-17 \%$ of ALN negative patients $[2,11,12]$. In patients with a negative axilla, a positive IMLN portends a similar prognosis as ALN positive patients, impacting both recurrence and survival [1-3]. The results of the MA.20 showed that the addition of regional nodal irradiation (including IMLNs) to whole-breast irradiation reduced the rate of breast-cancer recurrence in patients with node-positive or high-risk node-negative breast cancer [13]. The EORTC $22922 / 10925$ study found that regional nodal irradiation improved the rates of disease-free and distant diseasefree survival and reduced the rate of death from breast cancer among patients with early-stage breast cancer [14]. Furthermore, the DBCG-IMN study identified that IMLNs irradiation increased overall survival in patients with early-stage node-positive breast cancer [15]. The 2016 National Comprehensive Cancer Network Breast Cancer Clinical Practice Guidelines recommend radiotherapy to IMLNs for patients with $\geq 4$ positive ALNs (category 1), and strongly consider radiotherapy to IMLNs for patients with 1-3 positive axillary nodes (category $2 \mathrm{~A}$ ), both after mastectomy and lumpectomy [16]. However, lowrisk did not mean IMLN negative and high-risk did not mean IMLN metastases [17]. Studies of extended radical mastectomy reported that $36.8 \%-46.2 \%$ patients with $\geq 4$ positive ALNs and $18.8 \%-26.7 \%$ patients with $1-3$ positive ALNs identified IMLN metastases, and negative IMLN was found in about $70 \%$ patients with $\geq 4$ positive ALNs [1, 18-20]. Thus, these inclusion criteria might induce over- and under-treatment. Up to now, there have no reasonable methods to detect out metastasis in IMLN exactly. But IM-SLNB via intercostal space could make it possible - tailored IMLNs radiotherapy and minimally invasive staging [17]. Even though breast cancer staging has incorporated IM-SLNB concept since the $6^{\text {th }}$ edition of the American Joint Committee on Cancer, IM-SLNB has not been performed routinely [21]. The studies of 
Table 1: Descriptive characteristics of eligible patients $(\mathrm{N}=216)$

\begin{tabular}{|c|c|c|c|}
\hline Characteristic & No. & & $\%$ \\
\hline \multicolumn{4}{|l|}{ Age (years) } \\
\hline Median & & 50 & \\
\hline Range & & $27 \sim 79$ & \\
\hline$\leq 50$ & 119 & & 55.1 \\
\hline$>50$ & 97 & & 44.9 \\
\hline \multicolumn{4}{|l|}{ BMI } \\
\hline Median & & 24.1 & \\
\hline Range & & $17.2 \sim 33.5$ & \\
\hline \multicolumn{4}{|l|}{ Tumor size } \\
\hline Tis & 16 & & 7.4 \\
\hline $\mathrm{T} 1$ & 99 & & 45.8 \\
\hline $\mathrm{T} 2$ & 79 & & 36.6 \\
\hline $\mathrm{T} 3$ & 22 & & 10.2 \\
\hline \multicolumn{4}{|l|}{ Tumor location } \\
\hline UOQ & 92 & & 42.6 \\
\hline LOQ & 25 & & 11.6 \\
\hline UIQ & 48 & & 22.2 \\
\hline LIQ & 5 & & 2.3 \\
\hline Central & 46 & & 21.3 \\
\hline \multicolumn{4}{|l|}{ Tumor type } \\
\hline Ductal & 187 & & 86.6 \\
\hline Lobular & 8 & & 3.7 \\
\hline Mixed & 5 & & 2.3 \\
\hline Other & 16 & & 7.4 \\
\hline \multicolumn{4}{|c|}{ Radiotracer intensity (MBq) } \\
\hline Median & & 36 & \\
\hline \multicolumn{4}{|c|}{ Radiotracer volume (mL/point) } \\
\hline Median & & 0.5 & \\
\hline \multicolumn{4}{|c|}{ Intervals from injection to SLNB (h) } \\
\hline $2 \sim 5$ & 89 & & 41.2 \\
\hline $16 \sim 22$ & 127 & & 58.8 \\
\hline
\end{tabular}

Abbreviations: $B M I$ body-mass-index, $U O Q$ upper outer quadrant, $L O Q$ lower outer quadrant, UIQ upper inner quadrant, $L I Q$ lower inner quadrant.

IM-SLNB showed that the success rate of IM-SLNB has reached $60-100 \%$ with minimal or no changes in operative time [4-7], but the visualization rate of IM-SLN was low [6-8], which has been the restriction for both clinical study and daily practice of IM-SLNB (Table 6).
Clinical studies found that superficial injection (intradermal, subdermal, periareolar, and subareolar) of radiotracer was hard to identify IM-SLN but intraparenchymal injection (peritumoral, intratumoral, or subtumoral) was more reliable [33-38]. These results 
Table 2: Clinical outcome of patients who underwent IM-SLNB ( $N=145)$

\begin{tabular}{|c|c|c|}
\hline Characteristic & No. & $\%$ \\
\hline \multicolumn{3}{|l|}{ T Stage } \\
\hline Tis & 9 & 6.2 \\
\hline $\mathrm{T} 1$ & 70 & 48.3 \\
\hline $\mathrm{T} 2$ & 57 & 39.3 \\
\hline $\mathrm{T} 3$ & 9 & 6.2 \\
\hline \multicolumn{3}{|l|}{ N Stage } \\
\hline No & 70 & 48.3 \\
\hline N1 & 57 & 39.3 \\
\hline $\mathrm{N} 2$ & 7 & 4.8 \\
\hline N3 & 11 & 7.6 \\
\hline \multicolumn{3}{|l|}{ ER } \\
\hline Positive & 101 & 69.7 \\
\hline Negative & 44 & 30.3 \\
\hline \multicolumn{3}{|l|}{ PR } \\
\hline Positive & 98 & 67.6 \\
\hline Negative & 47 & 32.4 \\
\hline \multicolumn{3}{|l|}{ HER-2 } \\
\hline Positive & 44 & 30.3 \\
\hline Negative & 101 & 69.7 \\
\hline \multicolumn{3}{|l|}{ Type of surgery } \\
\hline Lumpectomy+ASLNB & 9 & 6.2 \\
\hline Lumpectomy+ALND & 3 & 2.1 \\
\hline Mastectomy+ASLNB & 93 & 64.1 \\
\hline Mastectomy+ALND & 40 & 27.6 \\
\hline \multicolumn{3}{|l|}{ Radiotherapy } \\
\hline WBI & 7 & 4.8 \\
\hline WBI+RNI & 5 & 3.5 \\
\hline $\mathrm{PMRT}+\mathrm{RNI}$ & 79 & 54.5 \\
\hline No & 54 & 37.2 \\
\hline \multicolumn{3}{|l|}{ Chemotherapy } \\
\hline Yes & 121 & 83.4 \\
\hline No & 24 & 16.6 \\
\hline
\end{tabular}

Abbreviations: $E R$ estrogen receptor status, $P R$ progesterone receptor status, $H E R-2$ human epidermal growth factor receptor-2, WBI whole breast irradiation, $R N I$ regional node irradiation, $P M R T$ postmastectomy radiotherapy.

suggest that the dermal and subdermal lymphatic flow is rarely directed to IMLNs, whereas some intraparenchymal lymphatic flow is directed to IMLNs. Anatomy study described that the breast parenchyma has extensive lymphatic network and has rich anastomoses with the superficial cutaneous lymph plexus of the developing skin [39]. It is considered that radiotracer, wherever injected, could flow to the same ASLN. That means ASLN receive the lymphatic drainage from not only the primary tumor area, but also the entire breast organ [10]. Based on 
Table 3: Details of IM-SLN mapping and biopsy

\begin{tabular}{|c|c|c|c|}
\hline Characteristic & No. & & $\%$ \\
\hline IM-SLN map+ & 155 & & $71.8(155 / 216)$ \\
\hline Pt. performed IM-SLNB & 149 & & $96.1(149 / 155)$ \\
\hline Success rate of IM-SLNB & 145 & & $97.3(145 / 149)$ \\
\hline Total No. of IM-SLN & & 279 & \\
\hline Median & & 2 & \\
\hline Range & & $1 \sim 4$ & \\
\hline IM-SLN metastatic & 18 & & $12.4(18 / 145)$ \\
\hline \multicolumn{4}{|l|}{ IM-SLNB time (min) } \\
\hline Median & & 10 & \\
\hline Range & & $3 \sim 55$ & \\
\hline \multicolumn{4}{|l|}{ IM-SLN size (mm) } \\
\hline Median & & 5 & \\
\hline Range & & $3 \sim 12$ & \\
\hline
\end{tabular}

this concept, the hypothesis of IM-SLN was supposed, which IM-SLN receives lymphatic drainage from not only the primary tumor area, but also the entire breast parenchyma. According to the hypothesis, a modified technique (periareolar intra-parenchyma, high volume, and ultrasonographic guidance) was formulated, which could significantly increase the preoperative visualization rate of the IM-SLN without lowering ASLN visualization rate $[8,38]$. The detection rate of IM-SLN was $71.1 \%$ in the modified technique group compare to $15.5 \%$ in the traditional technique group $(P<0.001)$, and the detection rate of ASLN was similar in both groups (98.9\% versus $98.3 \%, \mathrm{P}=0.712$ ) [38]. The visualization number of IMSLN was no difference between the modified technique group and the traditional tracer technique in our pilot study $(P=0.692)$. Also, the preoperative visualization number of IM-SLN was largely in accordance with other studies used tradition technique (peritumoral intraparenchymal injection) [40].

However, the radiotracer was not injected in peritumoral intra-parenchyma but in periareolar intraparenchyma with the modified technique based on the hypothesis. The question arises as to whether all nodes detected by the method should be considered as "true" IM-SLN or whether some of them are actually "secondtier" IMLN. The accuracy of the modified technique has been confirmed by our team at the previous study [41]. The hypothesis of ASLN lymphatic drainage pattern was proved with subsequent axillary lymph node dissection (ALND). As the extended radical mastectomy (included all IMLNs resection) has been abandoned since 1960s [42, 43], the hypothesis of IMSLN lymphatic drainage pattern cannot be validated by this way. Now, another method was used to validate the IM-SLN lymphatic drainage hypothesis. The ICG fluorescence tracer is a safe and effective method for SLNB in breast cancer with acceptable sensitivity and specificity comparable to conventional methods [44-46]. In our breast cancer center, it has been compared with the combined method (blue dye with radiotracer) in identifying ASLN. It showed that all ASLN identified by combined method also were ICG fluorescence positive and non-sentinel lymph nodes were ICG negative after ALND $(n=69, P<0.05)$. The internal mammary lymph nodes commonly receive less than $25 \%$ of the total lymph from the breast [47]. Due to little volume of ICG tracer is difficulty to detect by the fluorescence imaging system, it is hard to find IM-SLN by this tracer. But IM-SLN can be detected by radiotracer with the modified radiotracer injection technique and performed biopsy. In the validation study, the ICG fluorescence tracer was injected intraparenchymally at the peritumoral and the radiotracer was injected with the modified technique. By this method, to identify different tracers injected in different sites could reach to the same IM-SLN. After IM-SLNB the status of IMSLN was identified by intraoperative gamma probe and fluorescence imaging system. The radiotracer and the fluorescence tracer in the same IM-SLN showed a strong correlation coefficient at 0.836 (Case-base, $\left.\mathrm{r}_{\mathrm{s}}>0.5, P<0.05\right)$. The degree of agreement between the radiotracer and the fluorescence tracer was Kappa $=0.823$ 
Table 4: The clinical, pathological and treatment details of patients with positive IM-SLN

\begin{tabular}{lccccccccc}
\hline No. & $\begin{array}{c}\text { Tumor } \\
\text { location }\end{array}$ & T stage & $\begin{array}{c}\text { No. of } \\
\text { positive } \\
\text { ALN }\end{array}$ & $\begin{array}{c}\text { N stage } \\
\text { without } \\
\text { IM-SLN }\end{array}$ & $\begin{array}{c}\text { No. of } \\
\text { positive } \\
\text { IM-SLN }\end{array}$ & $\begin{array}{c}\text { N stage } \\
\text { with IM- } \\
\text { SLN }\end{array}$ & Finally stage & $\begin{array}{c}\text { Chemo- } \\
\text { Therapy }\end{array}$ & $\begin{array}{c}\text { Radio- } \\
\text { Therapy }\end{array}$ \\
\hline 1 & UOQ & T2 & 0 & pN0 & 2 & pN1b & IIA $\rightarrow$ IIB & Yes & No $\rightarrow$ Yes \\
2 & UIQ & T2 & 2 & pN1a & 1 & pN1c & IIB (no change) & Yes & $? \rightarrow$ Yes \\
3 & Central & T2 & 14 & pN3a & 1 & pN3b & IIIC (no change) & Yes & Yes \\
4 & UOQ & T2 & 9 & pN2a & 1 & pN3b & IIIA $\rightarrow$ IIIC & Yes & Yes \\
5 & UIQ & T1c & 2 & pN1a & 1 & pN1c & IIA (no change) & Yes & $? \rightarrow$ Yes \\
6 & UOQ & T2 & 1 & pN1a & 1 & pN1c & IIB (no change) & Yes & $? \rightarrow$ Yes \\
7 & UIQ & T1a & 0 & pN0 & 1 & pN1b & IA $\rightarrow$ IIA & No $\rightarrow$ Yes & No $\rightarrow$ Yes \\
8 & UOQ & T2 & 9 & pN2a & 2 & pN3b & IIIA $\rightarrow$ IIIC & Yes & Yes \\
9 & LIQ & T2 & 5 & pN2a & 1 & pN3b & IIIA $\rightarrow$ IIIC & Yes & Yes \\
10 & UOQ & T1a & 3 & pN1a & 1 & pN1c & IIA (no change) & Yes & $? \rightarrow$ Yes \\
11 & UIQ & T2 & 0 & pN0 & 1 & pN1b & IIA $\rightarrow$ IIB & Yes & No $\rightarrow$ Yes \\
12 & UOQ & T3 & 13 & pN3a & 1 & pN3b & IIIC (no change) & Yes & Yes \\
13 & Central & T1c & 1 & pN1a & 1 & pN1c & IIA (no change) & Yes & $? \rightarrow$ Yes \\
14 & UOQ & T2 & 13 & pN3a & 1 & pN3b & IIIC (no change) & Yes & Yes \\
15 & Central & T2 & 11 & pN3a & 1 & pN3b & IIIC (no change) & Yes & Yes \\
16 & UOQ & T2 & 20 & pN3a & 1 & pN3b & IIIC (no change) & Yes & Yes \\
17 & UOQ & T2 & 5 & pN2a & 1 & pN3b & IIIA $\rightarrow$ IIIC & Yes & Yes \\
18 & UIQ & T1c & 0 & pN0 & 1 & pN1b & IA $\rightarrow$ IIA & No $\rightarrow$ Yes & No $\rightarrow$ Yes \\
\hline
\end{tabular}

Abbreviations: $U O Q$ upper outer quadrant, UIQ upper inner quadrant, $L I Q$ lower inner quladrant, ? radiotherapy is controversy.

Table 5: Different tracers identified in IM-SLN

\begin{tabular}{lccc}
\hline Tracers map & Radiotracer + & Radiotracer- & Total \\
\hline Fluorescence tracer+ & 127 & 0 & 127 \\
Fluorescence tracer- & 18 & 71 & 89 \\
Total & 145 & 71 & 216 \\
\hline
\end{tabular}

(very good), showing high degree of agreement between the two tracers (Kappa $>0.8, P<0.05)$. It showed that the lymphatic drainage from different location of the breast (the primary tumor, the subareolar plexus) reached to the same IM-SLN, which means that IM-SLN receives lymphatic drainage from not only the primary tumor area but also the entire breast parenchyma. That means the hypothesis of IM-SLN lymphatic drainage pattern was demonstrated. Furthermore, IM-SLN detected by the modified technique could reflect the real lymphatic drainage of the whole breast parenchyma. In other words, the modified technique can detect the "true" sentinel node in the internal mammary chain. In the study, the results of the metastases site and the number of IM-SLNs were in accordance with the past study of extended radical mastectomy, which could reflect the accuracy of IM-SLNB indirectly [48-50]. There were no serious adverse events or reactions after the radiotracer injected guiding by the modified injection technique.

In sum, different tracers injected into the different sites of the intra-parenchyma reached the same IM-SLN, which demonstrates the hypothesis that IM-SLN receives the lymphatic drainage from not only the primary tumor area but also the entire breast parenchyma. 
Table 6: Currently studies results of IM-SLNB

\begin{tabular}{lccccc}
\hline First author & Year & Case & $\begin{array}{c}\text { IM-SLN } \\
\text { visualization } \% \\
\text { (Case) }\end{array}$ & $\begin{array}{c}\text { IM-SLNB success } \\
\text { \% (Case) }\end{array}$ & $\begin{array}{c}\text { IMLN positive \% } \\
\text { (Case) }\end{array}$ \\
\hline Dupont [22] & 2001 & 1470 & $2.4(36)$ & $100(36)$ & $13.9(5)$ \\
van der Ent [23] & 2001 & 256 & $25.4(65)$ & $63.1(41)$ & $26.8(11)$ \\
Paganelli [24] & 2002 & 400 & $15.8(63)$ & $93.7(59)$ & $8.5(5)$ \\
Estourgie [25] & 2003 & 691 & $21.7(150)$ & $86.7(130)$ & $70.0(14)$ \\
Farru's [26] & 2004 & 225 & $8.8(20)$ & $100(138)$ & $16.9(22)$ \\
Hong [27] & 2005 & 979 & $14.1(138)$ & $60.7(65)$ & $18.1(25)$ \\
Carcoforo [28] & 741 & $14.4(107)$ & $87.7(121)$ & $15.4(10)$ \\
Leidenius [29] & 2006 & 984 & $14.0(138)$ & $78.0(85)$ & $14.9(18)$ \\
Madsen [30] & 2006 & 506 & $21.5(109)$ & $70.9(139)$ & $23.5(20)$ \\
Heuts [5] & 2007 & 1008 & $19.4(196)$ & $92.5(161)$ & $72.3(86)$ \\
Bourre [31] & 2009 & 622 & $28.0(174)$ & $100(72)$ & $11.1(18)$ \\
Postma [4] & 2009 & 493 & $24.1(119)$ & $16.3(14)$ \\
Ozmen [32] & 2012 & 890 & $8.1(72)$ & $13.9(10)$ \\
\hline
\end{tabular}

\section{PATIENTS AND METHODS}

\section{Study design and patients}

From September 2013 to July 2015, 216 patients with core biopsy proved invasive breast cancer scheduled to receive preoperative tracers injection, who agreed with performing IM-SLNB as part of their breast cancer surgery, were recruited to the IM-SLNB study. Patients with previous invasive breast cancer, hypersensitivity to iodine or ICG, hyperthyroidism and patients who were either pregnant or lactating were excluded from the study.

Two different kinds of tracer were injected at different sites in this validation study. The radiotracer (1.0-1.2ml 9.25-18.5 MBq ${ }^{99 \mathrm{~m}}$ Tc-labeled sulfur colloid) was injected with the modified radiotracer injection technique. It was injected into intra-parenchyma at the 6 and 12 o'clock positions $0.5-1.0 \mathrm{~cm}$ from the areola guided by ultrasound (ALOKA-SSD-5000, ALOKA, Tokyo, Japan) 3-18h before surgery [8, $38]$. The fluorescence tracer $(1.0 \mathrm{ml} 0.5 \%$ ICG) was injected in the peritumoral intra-parenchyma guided by ultrasound just before the beginning of the peration. The radioactive IM-SLNs were detected by preoperative lymphoscintigraphy (Toshiba GCA 901AHG, Toshiba Corporation, Tokyo, Japan) (Figure 1) 30min before the surgery and gamma probe (Neoprobe, Neo2000 gamma detection system, Johnson \& Johnson New Brunswick, NJ, USA) during the surgery. IM-SLNB was performed for patients with the radioactive IM-SLNs. After IMSLNB, the fluorescent status of IM-SLN was identified with the fluorescence imaging system (Ming De, MD fluorescence imaging system, Langfang, People's Republic of China) (Figure 2). The number and the status of IM-SLNs were recorded to identify the IMSLN visualized rate and the concordance rate of the radiotracer and the fluorescence tracer. All IM-SLNs were assessed by routine pathology.

The study was conducted within a single institute (Breast Cancer Center, Shandong Cancer Hospital Affiliated to Shandong University). All patients gave informed consent to participate in the study which had approval from the Shandong Cancer Hospital Affiliated to Shandong University Research Ethics Board (No. SDTHEC20130324). Any immediate toxicity following injection of ICG and any adverse events during the study period were recorded during surgery and at the twoweek follow up appointment.

\section{Internal mammary sentinel lymph node biopsy}

During the operation, IM-SLNB was performed for patients with radioactive IM-SLNs via the intercostal space. Through the mastectomy incision or modified radical mastectomy incision access to the location of IM-SLNs under the guidance of intraoperative gamma probe. Then the pectoral major fascia muscle fibers were separated to expose the relevant intercostal space. Next, the external and internal intercostal muscles were 


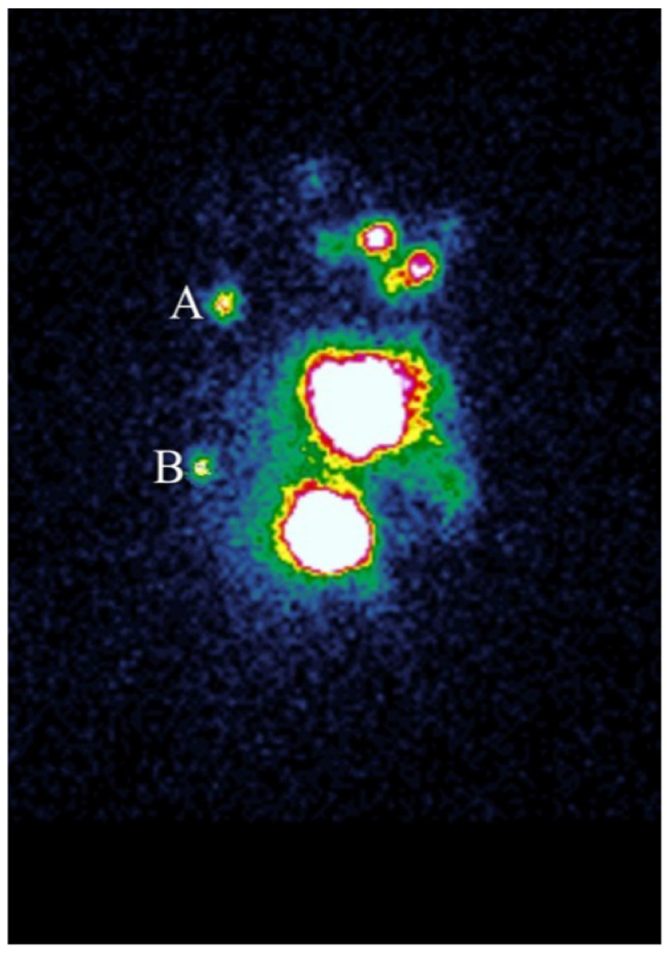

Figure 1: Preoperation lymphoscintigram with radiotracer. Hotspots are evidently shown in both the second intercostal space A. and the fourth intercostal space B. in patient with left-sided breast cancer.

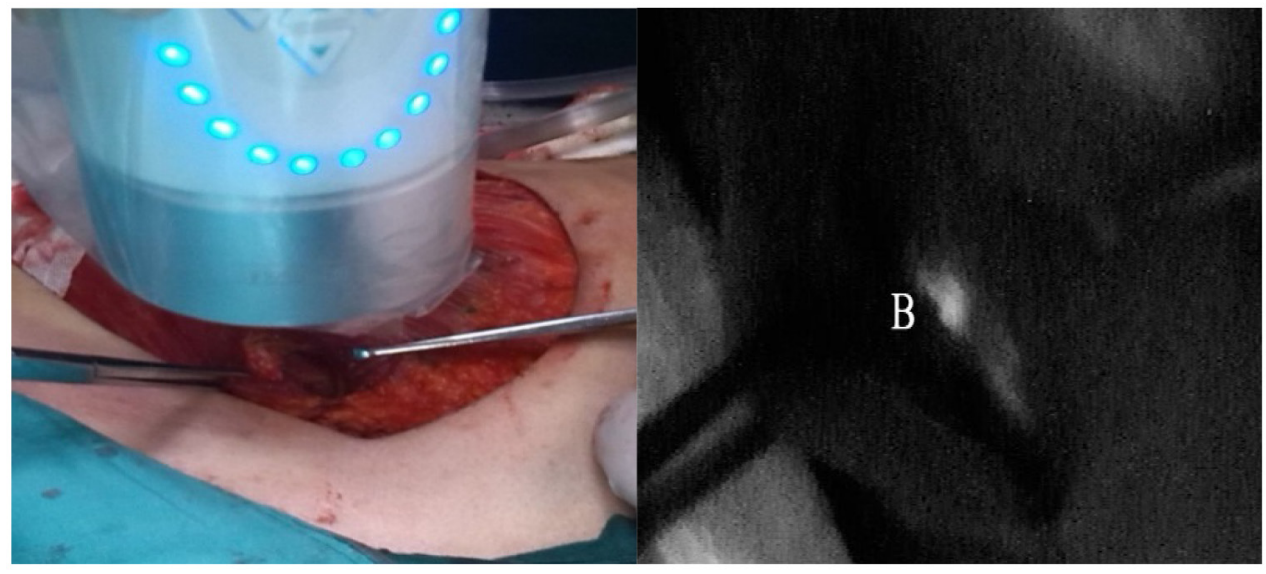

Figure 2: Intraoperative IM-SLNB identified the location of IM-SLN in the fourth intercostal space. The fluorescence imaging system showed the IM-SLN fluorescence tracer positive $\mathbf{B}$.

divided transversely in its middle. To avoid injury to the anterior intercostal vessels, the division should be located between the two costal cartilages or along the superior costal border. IM-SLNs located in other intercostal spaces were removed by the same method. A postoperative chest X-ray was performed in case of accidental pleural lesion.

In patients who accepted breast conserving surgery, if the location of primary tumor could not reach IMSLNB, an extra incision $(2.5-3.0 \mathrm{~cm})$ in the skin has to be made.

\section{Histopathology of sentinel lymph nodes}

All SLNs underwent pathological evaluation according to local protocol including serial sectioning at $2.0-3.0 \mathrm{~mm}$ followed by routine staining with Haematoxylin and Eosin.

\section{Statistical analysis}

The data were analyzed with the SPSS 17.0 software package. Chi-square-test or Fisher's-exact-test was 
performed to compare the visualization rates among the groups. The correlations between the radiotracer and the fluorescence tracer in the same IM-SLN were calculated using the Spearman rank correlation coefficient. The criteria for judging the size of the correlation coefficient were applied: correlations $<0.30$ are considered minor, correlations between $0.3-0.49$ are considered medium, and $\geq 0.5$ are considered strong. Cohen's kappa statistic was used to determine inter-examiner agreement. According to Altman's guidelines, it is poor when kappa scores $\leq 0.20$, fair when kappa between 0.21-0.40, moderate when kappa between 0.41-0.60, good when kappa 0.61-0.80, and very good when kappa $\geq 0.80$. Reported $P$ values represent twosided tests. Significance was defined as $P<0.05$.

\section{ACKNOWLEDGMENTS}

Wang YS had full access to all of the data in the study and takes responsibility for the integrity of the data and the accuracy of the data analysis. Design and conduct of the study: Wang YS, Yu JM. Collection: Cong BB, Qiu PF, Cao XS. Management: Wang YS, Liu YB, Yang GR. Analysis: Cong BB, Wang YS. Interpretation of the data: Wang YS, Yu JM, Cong BB. Preparation, review, or approval of the manuscript: Wang YS, Yu JM, Cong BB. We thank Tong Zhao, MA, Zheng-Bo Zhou, MA, Peng Chen, MA, Chun-Jian Wang, MA, ZhaoPeng Zhang, MA and Xiao Sun, MA from our breast cancer center. All six of these individuals contributed to study conduct, manuscript review, or both; none received compensation for their contributions. We thank Rogers W, PhD, an English teacher from University of Jinan, who contributed to revise the language of the manuscript. We also thank all of the investigators and their site research teams. Lastly, we wish to thank the brave patients with breast cancer who participated in this study and their caregivers. The work was supported by grants from the Graduate Innovation Foundation of University of Jinan (YCXB15006) and the Natural Science Foundation of Shandong Province (2014ZRC03036).

\section{CONFLICTS OF INTEREST}

There is no conflict of interest in the study.

\section{REFERENCES}

1. Veronesi U, Cascinelli N, Bufalino R, Morabito A, Greco M, Galluzzo D, Delle Donne V, De Lellis R, Piotti $\mathrm{P}$, Sacchini V. Risk of internal mammary lymph node metastases and its relevance on prognosis of breast cancer patients. Ann Surg. 1983;198:681-684.

2. Veronesi U, Cascinelli N, Greco M, Bufalino R, Morabito A, Galluzzo D, Conti R, De Lellis R, Delle Donne V, Piotti
P. Prognosis of breast cancer patients after mastectomy and dissection of internal mammary nodes. Ann Surg. 1985;202:702-707.

3. Cody HS 3rd, Urban JA. Internal mammary node status: a major prognosticator in axillary node-negative breast cancer. Ann Surg Oncol. 1995;2:32-37.

4. Caudle AS, Yi M, Hoffman KE, Mittendorf EA, Babiera GV, Hwang RF, Meric-Bernstam F, Sahin AA, Hunt KK. Impact of identification of internal mammary sentinel lymph node metastasis in breast cancer patients. Ann Surg Oncol. 2014;21:60-65.

5. Gnerlich JL, Barreto-Andrade JC, Czechura T, John JR, Turk MA, Kennedy TJ, Winchester DJ. Accurate staging with internal mammary chain sentinel node biopsy for breast cancer. Ann Surg Oncol. 2014;21:368-374.

6. Postma EL, van Wieringen S, Hobbelink MG, Verkooijen HM, van den Bongard HJ, Borel Rinkes IH, Witkamp AJ. Sentinel lymph node biopsy of the internal mammary chain in breast cancer. Breast Cancer Res Treat. 2012;134:735-741.

7. Heuts EM, van der Ent FW, von Meyenfeldt MF, Voogd AC. Internal mammary lymph drainage and sentinel node biopsy in breast cancer - A study on 1008 patients. Eur J Surg Oncol. 2009;35:252-257.

8. Qiu PF, Liu JJ, Liu YB, Yang GR, Sun X, Wang YS. A modified technology could significantly improve the visualization rate of the internal mammary sentinel lymph nodes in breast cancer patients. Breast Cancer Res Treat. 2012;136:319-321.

9. Canavese G, Gipponi M, Catturich A, Di Somma C, Vecchio C, Rosato F, Tomei D, Nicolò G, Carli F, Villa G, Agnese G, Bianchi P, Buffoni F, et al. Pattern of lymphatic drainage to the sentinel lymph node in breast cancer patients. J Surg Oncol. 2000;74:69-74.

10. Borgstein PJ, Meijer S, Pijpers RJ, van Diest PJ. Functional lymphatic anatomy for sentinel node biopsy in breast cancer: echoes from the past and the periareolar blue method. Ann Surg. 2000;232:81-89.

11. Cserni G, Szekeres JP. Internal mammary lymph nodes and sentinel node biopsy in breast cancer. Surg Oncol. 2001;10:25-33.

12. Morrow M, Foster RS Jr. Staging of breast cancer: a new rationale for internal mammary node biopsy. Arch Surg. 1981;116:748-751.

13. Whelan TJ, Olivotto IA, Parulekar WR, Ackerman I, Chua BH, Nabid A, Vallis KA, White JR, Rousseau P, Fortin A, Pierce LJ, Manchul L, Chafe S, et al. Regional nodal irradiation in early-stage breast cancer. N Engl J Med. 2015;373:307-316.

14. Poortmans PM, Collette S, Kirkove C, Van Limbergen E, Budach V, Struikmans H, Collette L, Fourquet A, Maingon P, Valli M, De Winter K, Marnitz S, Barillot I, et al. Internal mammary and medial supraclavicular irradiation in breast cancer. N Engl J Med. 2015;373:317-327. 
15. Thorsen LB, Offersen BV, Danø H, Berg M, Jensen I, Pedersen AN, Zimmermann SJ, Brodersen HJ, Overgaard M, Overgaard J. DBCG-IMN: A population-based cohort study on the effect of internal mammary node irradiation in early node-positive breast cancer. J Clin Oncol. 2016;34:314-320.

16. Gradishar WJ, Anderson BO, Balassanian R, Blair SL, Burstein HJ, Cyr A, Elias AD, Farrar WB, Forero A, Giordano SH, Goetz M, Goldstein LJ, Hudis CA, et al. NCCN clinical practice guidelines in oncology: Breast Cancer. Version 1. 2016. NCCN.org.

17. Cong BB, Qiu PF, Wang YS. Internal mammary sentinel lymph node biopsy: minimally invasive staging and tailored internal mammary radiotherapy. Ann Surg Oncol. 2014;21:2119-2121.

18. Noguchi M, Yabushita K, Tajiri K, Fujii H, Miyazaki I. Five year results of radical mastectomy for breast cancer, by a sternal splitting, intrapleural en bloc resection of the internal mammary lymph nodes. Jpn J Surg. 1987;17:63-71.

19. Noguchi M, Ohta N, Thomas M, Kitagawa H, Miyazaki I. Risk of internal mammary lymph node metastases and its prognostic value in breast cancer patients. J Surg Oncol. 1993;52:26-30.

20. Huang O, Wang L, Shen K, Lin H, Hu Z, Liu G, Wu J, Lu J, Shao Z, Han Q, Shen Z. Breast cancer subpopulation with high risk of internal mammary lymph nodes metastasis: analysis of 2,269 Chinese breast cancer patients treated with extended radical mastectomy. Breast Cancer Res Treat. 2008;107:379-387.

21. Connolly JL. Changes and problematic areas in interpretation of the AJCC Cancer Staging Manual, 6th Edition, for breast cancer. Arch Pathol Lab Med. 2006;130:287-291.

22. Dupont EL, Salud CJ, Peltz ES, Nguyen K, Whitehead GF, Ku NN, Reintgen DS, Cox CE. Clinical relevance of internal mammary node mapping as a guide to radiation therapy. Am J Surg. 2001;182:321-324.

23. van der Ent FW, Kengen RA, van der Pol HA, Povel JA, Stroeken HJ, Hoofwijk AG. Halsted revisited: internal mammary sentinel lymph node biopsy in breast cancer. Ann Surg. 2001;234:79-84.

24. Paganelli G, Galimberti V, Trifirò G, Travaini L, De Cicco C, Mazzarol G, Intra M, Rocca P, Prisco G, Veronesi U. Internal mammary node lymphoscintigraphy and biopsy in breast cancer. Q J Nucl Med. 2002;46:138-144.

25. Estourgie $\mathrm{SH}$, Tanis PJ, Nieweg OE, Valdés Olmos RA, Rutgers EJ, Kroon BB. Should the hunt for internal mammary chain sentinel nodes begin? An evaluation of 150 breast cancer patients. Ann Surg Oncol. 2003;10:935-941.

26. Farrús B, Vidal-Sicart S, Velasco M, Zanón G, Fernández PL, Muñoz M, Santamaría G, Albanell J, Biete A. Incidence of internal mammary node metastases after a sentinel lymph node technique in breast cancer and its implication in the radiotherapy plan. Int J Radiat Oncol Biol Phys. 2004;60:715-721.

27. Hong J, Choy E, Soni N, Carmalt H, Gillett D, Spillane AJ. Extra-axillary sentinel node biopsy in the management of early breast cancer. Eur J Surg Oncol. 2005;31:942-948.

28. Carcoforo P, Sortini D, Feggi L, Feo CV, Soliani G, Panareo S, Corcione S, Querzoli P, Maravegias K, Lanzara $\mathrm{S}$, Liboni A. Clinical and therapeutic importance of sentinel node biopsy of the internal mammary chain in patients with breast cancer: A single-center study with long-term follow-up. Ann Surg Oncol. 2006;13:1338-1343.

29. Leidenius MH, Krogerus LA, Toivonen TS, Leppänen EA, von Smitten KA. The clinical value of parasternal sentinel node biopsy in breast cancer. Ann Surg Oncol. 2006;13:321-326.

30. Madsen E, Gobardhan P, Bongers V, Albregts M, Burgmans J, De Hooge P, Van Gorp J, van Dalen T. The impact on post-surgical treatment of sentinel lymph node biopsy of internal mammary lymph nodes in patients with breast cancer. Ann Surg Oncol. 2007;14:1486-1492.

31. Bourre JC, Payan R, Collomb D, Gallazzini-Crepin C, Calizzano A, Desruet MD, Pasquier D, Bolla M, Fagret D, Vuillez JP. Can the sentinel lymph node technique affect decisions to offer internal mammary chain irradiation? Eur J Nucl Med Mol Imaging. 2009;36:758-764.

32. Ozmen V, Ozcinar B, Bozdogan A, Eralp Y, Yavuz E, Dincer M. The effect of internal mammary lymph node biopsy on the therapeutic decision and survival of patients with breast cancer. Eur J Surg Oncol. 2015;41:1368-1372.

33. Shimazu K, Tamaki Y, Taguchi T, Motomura K, Inaji $\mathrm{H}$, Koyama $\mathrm{H}$, Kasugai $\mathrm{T}$, Wada A, Noguchi S. Lymphoscintigraphic visualization of internal mammary nodes with subtumoral injection of radiotracer in patients with breast cancer. Ann Surg. 2003;237:390-398.

34. Park C, Seid P, Morita E, Iwanaga K, Weinberg V, Quivey J, Hwang ES, Esserman LJ, Leong SP. Internal mammary sentinel lymph node mapping for invasive breast cancer: Implications for staging and treatment. Breast J. 2005;11:29-33.

35. Rodier JF, Velten M, Wilt M, Martel P, Ferron G, VainiElies V, Mignotte H, Brémond A, Classe JM, Dravet F, Routiot T, de Lara CT, Avril A, et al. Prospective multicentric randomized study comparing periareolar and peritumoral injection of radiotracer and blue dye for the detection of sentinel lymph node in breast sparing procedures: FRANSENODE trial. J Clin Oncol. 2007;25:3664-3669.

36. Wang L, Yu JM, Wang YS, Zuo WS, Gao Y, Fan J, Li JY, Hu XD, Chen ML, Yang GR, Zhou ZB, Liu YS, Li $Y Q$, et al. Preoperative lymphoscintigraphy predicts the successful identification but is not necessary in sentinel lymph nodes biopsy in breast cancer. Ann Surg Oncol. 2007; 14:2215-2220. 
37. Sun X, Liu JJ, Wang YS, Wang L, Yang GR, Zhou ZB, Li YQ, Liu YB, Li TY. Roles of preoperative lymphoscintigraphy for sentinel lymph node biopsy in breast cancer patients. Jap J Clin Oncol. 2010;40: $722-725$.

38. Qiu PF, Cong BB, Zhao RR, Yang GR, Liu YB, Chen P, Wang YS. Internal mammary sentinel lymph node biopsy with modified injection technique: high visualization rate and accurate staging. Medicine (Baltimore). 2015;94:e1790.

39. Tanis PJ, Nieweg OE, Valdés Olmos RA, Kroon BB. Anatomy and physiology of lymphatic drainage of the breast from the perspective of sentinel node biopsy. J Am Coll Surg. 2001;192:399-409.

40. Blumgart EI, Uren RF, Nielsen PM, Nash MP, Reynolds HM. Lymphatic drainage and tumour prevalence in the breast: a statistical analysis of symmetry, gender and node field independence. J Anat. 2011;218:652-659.

41. Cong BB, Cao XS, Qiu PF, Liu YB, Zhao T, Chen P, Wang CJ, Zhang ZP, Sun X, Wang YS. Validation study of the modified injection technique for internal mammary sentinel lymph node biopsy in breast cancer. Onco Targets Ther. 2015;8:2705-2708.

42. Lacour J, Bucalossi P, Cacers E, Jacobelli G, Koszarowski T, Le M, Rumeau-Rouquette C, Veronesi U. Radical mastectomy versus radical mastectomy plus internal mammary dissection. Five-year results of an international cooperative study. Cancer. 1976;37:206-214.
43. Lacour J, Le M, Caceres E, Koszarowski T, Veronesi U, Hill C. Radical mastectomy versus radical mastectomy plus internal mammary dissection. Ten year results of an international cooperative trial in breast cancer. Cancer. 1983;51:1941-1943.

44. Wishart GC, Loh SW, Jones L, Benson JR. A feasibility study (ICG-10) of indocyanine green (ICG) fluorescence mapping for sentinel lymph node detection in early breast cancer. Eur J Surg Oncol. 2012;38:651-656.

45. Hirche C, Murawa D, Mohr Z, Kneif S, Hünerbein M. ICG fluorescence-guided sentinel node biopsy for axillary nodal staging in breast cancer. Breast Cancer Res Treat. 2010;121:373-378.

46. Ahmed M, Purushotham AD, Douek M. Novel techniques for sentinel lymph node biopsy in breast cancer: a systematic review. Lancet Oncol. 2014;15:e351-362.

47. TURNER-WARWICK RT. The lymphatics of the breast. Br J Surg. 1959;46:574-582.

48. Livingston SF, Arlen M. The extended extrapleural radical mastectomy: its role in the treatment of carcinoma of the breast. Ann Surg. 1974;179:260-265.

49. Urban JA, Marjani MA. Significance of internal mammary lymph node metastases in breast cancer. Am J Roentgenol Radium Ther Nucl Med. 1971;111:130-136.

50. Horino T, Fujita M, Ueda N, Ota J, Ryo M, Nakano Y, Taguchi T. Efficacy of internal mammary node dissection in the treatment of breast cancer. Jpn J Clin Oncol. 1991;21:422-427. 